\title{
An invitation for more research on transnational corporations and the biosphere
}

To the Editor - We welcome the interest in our work on transnational corporations (TNCs) and biosphere stewardship. TNCs have rarely been linked to ecosystem dynamics, and even less so considered suitable partners for knowledge co-production in sustainability research. How TNCs shape the intertwined nature of people and planet therefore represents a timely and critical topic and the Correspondence articles by Schneider et al. and Etzion offer some important forwardlooking research questions.

The Correspondence by Schneider et al. focuses on important tensions in corporate sustainability, several of which are addressed in the literature cited in our Perspective. The authors emphasize the past record of specific types of TNCs in generating unsustainability and driving undesirable social outcomes and inequality to, in effect, oppose the proposition that TNCs could become active agents of systemic change towards sustainability.

Our analysis recognizes and documents the dominance of TNCs as a critical feature of the Anthropocene and highlights their disproportionate and unprecedented capacity to influence the biosphere. The significance of sovereign governments to implement effective public policies and improve governmental regulations is stressed as instrumental. Yet, our further contribution is to explore possible ways to leverage the unique position of TNCs to accelerate sustainability and increase their accountability in relation to unsustainable practices.

As Etzion suggests, TNCs differ widely in their agency and effectiveness. He points to critical empirical questions in this context, on how, and if, diversely motivated and constituted TNCs can contribute to change towards the Sustainable Development Goals. He emphasizes the diverse incentives that may apply to different sectors, and which actors in society and supply chains can produce such incentives. In particular, the notion of identifying different TNC archetypes offers an exciting avenue for exploring the social, political, economic, ecological and equity dimensions of TNC dominance - and what to do about it.

Corporate leaders increasingly regard sustainability as key for their business and a chance for companies to add value and to access emerging markets. This presents both opportunities and risks. The opportunity is for the private sector to assume leadership, engage in more sustainable practices and contribute to just transitions. The risk is that companies define the sustainability agenda in a way that is convenient for their operations and legitimates self-regulations over national or international rules, failing to address major social and environmental issues in their respective sectors, or falling short of delivering results in the absence of enforcement.

Our paper, and those by the commentators, represents an invitation for more research across scientific disciplines on how to engage with TNCs in ways that help meet the Sustainable Development Goals, and that ensure both transparent decisionmaking and improved regulation in the absence of stewardship.

Carl Folke (D) 1,2,3凶, Henrik Österblom (D)2, Jean-Baptiste Jouffray (D) 2,3, Eric F. Lambin ${ }^{4,5}$, W. Neil Adger ${ }^{106}{ }^{6}$, Marten Scheffer ${ }^{7}$, Beatrice I. Crona (D) 2,3, Magnus Nyström (D)2, Simon A. Levin' ${ }^{8}$, Stephen R. Carpenter (ID), John M. Anderies (D) 1,10, Stuart Chapin III"1, Anne-Sophie Crépin (D) 1,2, Alice Dauriach ${ }^{3}$, Victor Galaz (D) 1,2,3, Line J. Gordon²,
Nils Kautsky ${ }^{12}$, Brian H. Walker ${ }^{13}$, James R. Watson ${ }^{3,14}$, James Wilen ${ }^{15}$ and Aart de Zeeuw ${ }^{16}$

${ }^{1}$ Beijer Institute of Ecological Economics, Royal Swedish Academy of Sciences, Stockholm, Sweden. ${ }^{2}$ Stockholm Resilience Centre, Stockholm University, Stockholm, Sweden. ${ }^{3}$ Global Economic Dynamics and the Biosphere Academy Program (GEDB), Royal Swedish Academy of Sciences, Stockholm, Sweden. ${ }^{4}$ School of Earth, Energy \& Environmental Sciences, and Woods Institute for the Environment, Stanford University, Stanford, CA, USA. ${ }^{5}$ Georges Lemaître Earth and Climate Research Centre, Earth and Life Institute, Université catholique de Louvain, Louvain-la-Neuve, Belgium. ${ }^{6}$ Geography, College of Life and Environmental Science, University of Exeter, Exeter, UK. ${ }^{7}$ Aquatic Ecology and Water Quality, Department of Environmental Sciences, Wageningen University, Wageningen, Netherlands. ${ }^{8}$ Department of Ecology and Evolutionary Biology, Princeton University, Princeton, NJ, USA. ${ }^{9}$ Center for Limnology, University of Wisconsin-Madison, Madison, WI, USA. ${ }^{10}$ School of Human Evolution and Social Change, School of Sustainability, Arizona State University, Tempe, AZ, USA. ${ }^{11}$ Institute of Arctic Biology, University of Alaska Fairbanks, Fairbanks, AK, USA. ${ }^{12}$ Department of Ecology, Environment and Plant Sciences, Stockholm University, Stockholm, Sweden. ${ }^{13}$ CSIRO Sustainable Ecosystems, Canberra, Australian Capital Territory, Australia. ${ }^{14}$ College of Earth, Ocean and Atmospheric Sciences, Oregon State University, Corvallis, OR, USA. ${ }^{15}$ Department of Agricultural and Resource Economics, University of California, Davis, Davis, CA, USA. ${ }^{16}$ Department of Economics, CentER and TSC, Tilburg University, Tilburg, Netherlands.

$\bigotimes_{e-m a i l: c a r l . f o l k e @ b e i j e r . k v a . s e}$

Published online: 28 February 2020

https://doi.org/10.1038/s41559-020-1145-2

Competing interests

The authors declare no competing interests. 